\title{
Chemoreception in the salmon louse Lepeophtheirus salmonis: an electrophysiology approach
}

\author{
D. M. Fields ${ }^{1,2, *}$, M. J. Weissburg ${ }^{3}$, H. I. Browman ${ }^{2}$ \\ ${ }^{1}$ Bigelow Laboratory for Ocean Sciences, PO Box 475, West Booth Bay Harbor, Maine 04575, USA \\ ${ }^{2}$ Institute of Marine Research, Austevoll Research Station, 5392 Storebø, Norway \\ ${ }^{3}$ Georgia Institute of Technology, Atlanta, Georgia, USA
}

\begin{abstract}
The search for effective and long-term solutions to the problems caused by salmon lice Lepeophtheirus salmonis (Krøyer, 1837) has increasingly included biological/ecological mechanisms to combat infestation. One aspect of this work focuses on the host-associated stimuli that parasites use to locate and discriminate a compatible host. In this study we used electrophysiological recordings made directly from the antennule of adult lice to investigate the chemosensitivity of $L$ salmonis to putative chemical attractants from fish flesh, prepared by soaking whole fish tissue in seawater. There was a clear physiological response to whole fish extract (WFX) with threshold sensitivity at a dilution of $10^{-4}$. When WFX was size fractionated, L. salmonis showed the greatest responses to the water-soluble fractions containing compounds between 1 and $10 \mathrm{kDa}$. The results suggest that the low molecular weight, water-soluble compounds found in salmon flesh may be important in salmon lice host choice.
\end{abstract}

KEY WORDS: Lepeophtheirus salmonis $\cdot$ Electrophysiology $\cdot$ Olfaction $\cdot$ Host finding

\section{INTRODUCTION}

The salmon louse Lepeophtheirus salmonis (Krøyer, 1837 ) is an ectoparasitic copepod that infests both wild and farmed salmonid fish of the genera Salmo, Salvelinus and Oncorhynchus (Pike \& Wadsworth 1999, Costello 2006, Hilborn, 2006). Salmon lice are a major disease problem in farmed fish and they have been implicated in the decline of some wild anadromous stocks of Atlantic salmon Salmo salar L. (e.g. Finstad et al. 2000, Hilborn 2006, Krkosek et al. 2006). The search for effective and long-term solutions to the problems caused by salmon lice has historically focused on delousing treatments. However, recent efforts have been directed at improving our knowledge of the parasite's biology that is relevant to controlling their ability to exploit host populations. One aspect of this work focuses on the host-associated stimuli that parasites might use to locate and discriminate a compatible host (e.g. Buchmann \& Nielsen 1999, Haas et al. 2002, Haas 2003, Mikheev et al. 2004, Beamish et al. 2005).

The sensory modalities and behaviors involved in host detection and recognition by Lepeophtheirus salmonis are likely to consist of a hierarchy within which one or more senses operate simultaneously, depending on proximity to the potential host. L. salmonis can detect a range of environmental and host-related stimuli, e.g. pressure/moving water, light, salinity, temperature and semiochemicals (Wootten et al. 1982, Bron et al. 1993, Heuch \& Karlsen 1997, Devine et al. 2000, Ingvarsdóttir et al. 2002a,b, Luntz 2003, Beamish et al. 2005, Bailey et al. 2006). Visual cues, such as a decrease in light intensity resulting from shadows of fish swimming overhead, would operate at long range, i.e. meters to tens of meters (Flamarique et al. 2000). Rapid decreases in light intensity give rise to an increase in the 
overall activity level of the salmon louse and/or alter its swimming pattern, stimulating it to move upward through the water column (Flamarique et al. 2000, Mikheev et al. 2003). Similarly, diffuse chemical cues devoid of a spatial or temporal gradient, such as the odorants released from a large group of salmon on a migratory run or in sea cages, also give rise to a general increase in swimming speeds (P. Kuhn et al. unpubl.) and may operate over relatively long distances. Synergistic effects of different sensory systems are also likely to play an important role in long-range host detection. For example, a diffuse, host-related chemical cue could modulate the louse response to visual cues, as is the case for Argulus coregoni, which located hosts more effectively using vision when olfac-

tory cues were present (Mikheev et al. 2004). These broadly distributed light and chemical signals provide no clear mechanism for the louse to orient towards a specific host. Rather, such cues can increase the activity level of L. salmonis and may lead to higher random encounter rates, or movement into regions where more specific cues are available. On smaller spatiotemporal scales, perhaps only a few centimetres from the host, chemical trails (Weissburg 1997, Doall et al. 1998, Okubo et al. 2001, Ingvarsdóttir et al. 2002a,b) or fluid mechanical signals (e.g. Fields \& Yen 2002, Yen \& Okubo 2002) associated with an individual fish may provide directional signals that allow the louse to accurately leap towards a specific host. This also appears to be true for salmon lice copepodids and adults, which are attracted to strong chemical sources emanating from a y-maze (Ingvarsdóttir et al. 2002a, Bailey et al. 2006) or for the response of copepodids to fluid mechanical signals created by a moving silicone cast of a salmon head (Heuch et al. 2007). At this scale, it is critical that $L$. salmonis is able to perform an accurately directed leap towards a potential host. Finally, at settlement, chemical and potentially tactile cues associated with the surface of the host are probably critical to the final decision to remain associated with a given host (e.g. Buchmann \& Bresciani 1997).

In the present study we investigated the chemosensitivity of adult Lepeophtheirus salmonis to extracts of putative chemical attractants from fish flesh. Our goal was to determine the potential role of chemical cues in mediating the final phases of attraction and host identification. Electrophysiological recordings were made directly from the antennule of adult animals using concentrations expected to be found within the centimeter to meter range of distance from a potential host.

\section{MATERIALS AND METHODS}

Lepeoptheirus salmonis collection and culture. Adult male and female salmon lice L. salmonis were collected from live salmon Salmo salar maintained in commercial sea cages, in tanks, or from salmon at a local slaughter facility. Adult lice were transported in ice chests to the Austevoll Research Station, Storebø, Norway, and allowed to re-infect caged salmon maintained at the station. Salmon and salmon lice were maintain at $8^{\circ} \mathrm{C}$ in $1000 \mathrm{l}$ circulation tanks for a maximum of $2 \mathrm{wk}$.

Chemostimulants. A fresh salmon was euthanized and cubed into 10 to $15 \mathrm{~g}$ aliquots with each cube containing a portion of muscle, skin and associated mucus. A stock solution (Fig. 1) of chemostimulant was prepared by soaking individual aliquots in filtered seawater (FSW: $0.2 \mu \mathrm{m}$ ) at a 1:10 dilution for $1 \mathrm{~h}$ at $0^{\circ} \mathrm{C}$. The liquid portion (whole fish extract: WFX) was filtered (Whatman GFC filters; $1.2 \mu \mathrm{m})$ and frozen $\left(-40^{\circ} \mathrm{C}\right)$ for future use. Preliminary experiments demonstrated that there was no difference in neural activity in response to WFX prepared from fresh or frozen material. Serial dilutions of this WFX primary stock were used to characterize the dose-response functions of L. salmonis chemosensory neurons (see below).

We used 2 techniques to partially characterize the properties of potential chemical attractants. Size fractionations of WFX were performed by standard dialysis techniques using dialysis membranes with 2 size cutoffs; 1 and $10 \mathrm{kDa}$. We harvested both the filtrate passing through the membrane and the retentate blocked by the membrane to produce 4 size fractions: $>1 \mathrm{kDa}_{;}<1 \mathrm{kDa}$; $>10 \mathrm{kDa}$; and <10 kDa. Dialysis took place using FSW chilled to $0^{\circ} \mathrm{C}$, for $4 \mathrm{~h}$ at an ambient 
temperature of $4{ }^{\circ} \mathrm{C}$. Filtrate and retentate were diluted to a concentration of $10^{-1}$ relative to WFX and was stored at $-40^{\circ} \mathrm{C}$ for future use.

Polar and non-polar fractions were generated by mixing equal volumes of WFX and diethyl-ether (DE) in a separatory funnel for $2 \mathrm{~h}$ at $4^{\circ} \mathrm{C}$. The aqueous solution was collected and frozen for later use to determine if the water-soluble fraction continued to retain activity. The DE fraction was washed 3 times with fresh FSW, then separated from the water and allowed to evaporate overnight. The remaining residue was redissolved with DMSO (dimethyl sulfoxide; spectophotometric grade, Fisher Scientific) and frozen into $75 \mu \mathrm{l}$ aliquots for later use. The DE and water-soluble fractions were diluted to a $10^{-1}$ equivalent dilution (relative to WFX) prior to testing in electrophysiological assays. A $0.5 \%$ DMSO solution was used as a control for the solvent carrier of the DE fraction

Electrophysiological experiments. Adult Lepeophtheirus salmonis were removed from their host and restrained ventral side up in a Syl-Guard (non-toxic silicone elastomer) filled Petri dish ( $4 \mathrm{~cm}$ diameter) using insect pins (\# 000). The temperature was maintained between 8 to $10^{\circ} \mathrm{C}$ by placing the entire Petri dish within an ice bath. The experimental antennule was exposed to a constant flow of ambient seawater at 1 to $2 \mathrm{ml} \mathrm{min}^{-1}$ throughout the experiment to normalize the activity due to mechanoreception and to standardize the rate of delivery of all chemical signals. Chemical signals, and all controls, were introduced to the antennule via an $800 \mu \mathrm{m}$ capillary tube pulled to an outer diameter of $\sim 200 \mu \mathrm{m}$, which was positioned perpendicular to the antennules such that the fluids washed over the entire antennule.

The test antennule was pierced at the distal tip using an insulated $5 \mathrm{M} \Omega$ tungsten probe (FHC) with a $1 \mu \mathrm{m}$ exposed recording tip. Although we surveyed a variety of sites along the antennules, the distal region consistently produced the highest probability of recording clear action potentials and we subsequently confined our recordings to these sites. This area is near the antennal nerve containing axons from chemosensory cells on the antennule. From these sites we were able to simultaneously record electrical signals from numerous individual neurons.

The voltage signal was normalized to a silver reference wire mounted in the water bath and amplified $100 \times$ using a DC pre-amplifier and secondarily amplified up to an additional 40× using an APM analog-todigital interface (FHC), and subsequently stored on digital tape using a Sony DTC-ZE700 retrofitted for neurophysiological recordings. Signals were prefiltered for 50/60 cycle noise using a HumBug (Questscientific Instruments). The data was analyzed off-line by inputting the recorded signals into signal processing software (Datawave) and the neural responses sorted based on their waveform characteristics (e.g. peak and valley amplitude, rise time, offset slope) in order to identify individual neurons. We used this analysis to determine instantaneous spike frequency and the number of spikes occurring in response to each stimulus presentation. All responses were corrected for background activity in response to FSW and, where appropriate, control solutions.

Experimental trials consisted of challenging the chemosensors along the antennules with WFX, polar and DE fractions and the 4 molecular weight fractions. Initial experiments used only WFX diluted to $10^{-1}-10^{-4}$ using FSW to obtain dose response functions. In subsequent experiments, neurons showing a clear dose response to WFX dilutions were also tested with the complete set of isolated size and polarity fractions of the WFX. Each trial lasted for $30 \mathrm{~s}$, and individual treatments were separated by a $60 \mathrm{~s}$ FSW control to monitor background activity and wash chemical residue from the region surrounding the antennule (see Fig. 3). Between trials, the contents of the dish was gently drained by suction from a small (1 mm diameter) pipette without disturbing the louse or exposing it to air. The dose-response series was presented in ascending order, and thereafter, the polarity and molecular weight fractions (at a concentration of $10^{-1}$ relative to WFX) were presented randomly. We included WFX approximately every fifth stimulus presentation, and at the end of the suite of tested stimuli, to control for changes in nerve cell sensitivity. All data come from neurons that were exposed to the entire set of stimuli. We discarded data from any neuron in which the coefficient of variation of the response to WFX exceeded $20 \%$. The raw responses were normalized to account for variations in spike frequency across individual neurons; responses to the dose series were normalized to the peak response of a given neuron (typically, but not always, observed at full strength WFX; see 'Results') whereas responses to fractions were normalized by the responses to the equivalent dilution of WFX, which was $10^{-1}$. Sensitivity to the various fractions was analyzed by ANOVA followed by Tukey's post-hoc test to determine significant differences across the individual treatments. Data were not transformed since there were no significant departures from normality.

\section{RESULTS}

The antennule is the primary structure for chemoand mechanoreception for copepods (Fields et al. 2002). We recorded chemosensory responses from 20 chemosensory neurons in 13 male and female Lepeophtheirus salmonis. A typical recording contained 


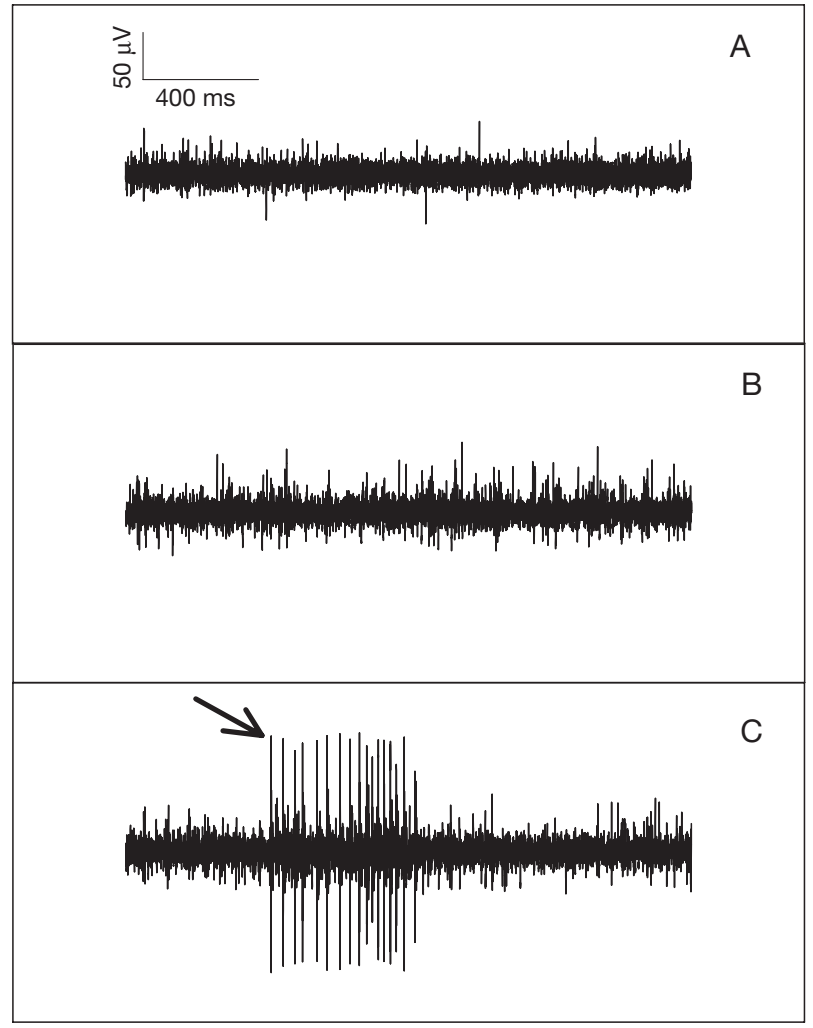

Fig. 2. Lepeophtheirus salmonis. Neurophysiology recorded from the antennule of a louse in response to (A) filtered seawater (FSW: control), (B) $10^{-1}$ dilution of whole fish extract (WFX), and (C) undiluted WFX. Traces represent $2 \mathrm{~s}$ of data collected at $48 \mathrm{kHz}$. Scale bars shown in (A) with voltage on the ordinate and time on the abscissa. Arrow shows large spikes as a result of leg muscle contractions

activity from 1 to 4 identifiable neurons. Instantaneous spike frequencies to full strength WFX ranged from approximately 0.5 to 100 spikes $\mathrm{s}^{-1}$, with background activity ranging from 0 to 20 spikes $\mathrm{s}^{-1}$

The data shows a clear physiological response to WFX with greater firing frequency in the presence of WFX than in flowing FSW (Fig. 2A,B). Stimulation by full strength WFX was often followed by bursts of strong motor neuron activity (Fig. 2C), which were clearly distinguishable by their large amplitude relative to the chemosensory action potentials. These responses typically occurred at the higher doses of WFX, were quite regular, and occurred in conjunction with visible movement of the antennule or legs. The neurophysiological response was repeatable within a single louse (Fig. 3), showing little evidence of adaptation carried over to subsequent trials. This observation suggested that the $60 \mathrm{~s}$ flushing of the chamber was sufficient to remove stimuli from the previous trial. In general, the neural activity for all the lice tested showed a rapid increase in firing frequency in

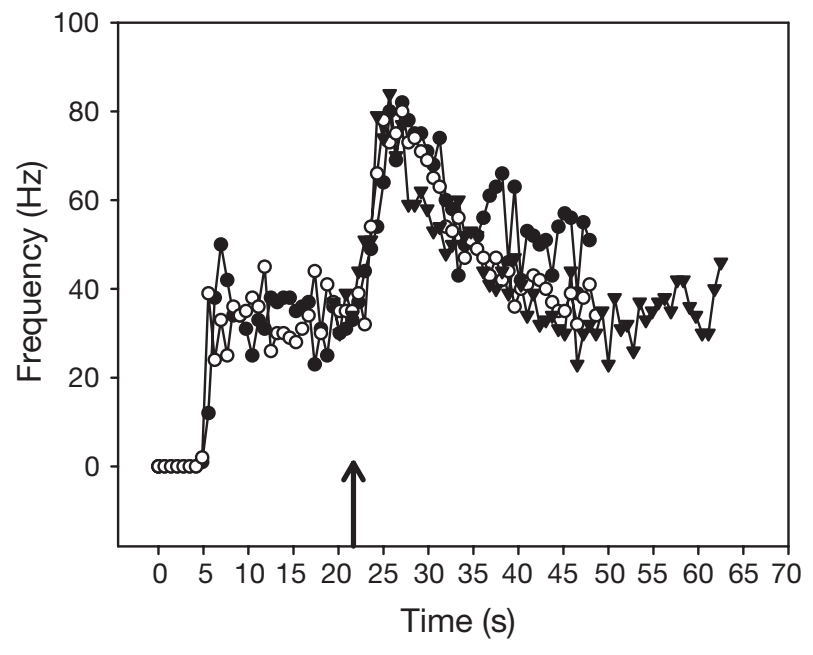

Fig. 3. Lepeophtheirus salmonis. Time series of the average spike frequency (binned in $1 \mathrm{~s}$ intervals) of lice in response to a dilution of $10^{-2}$ whole fish extract (WFX). Data was recorded for $\sim 20 \mathrm{~s}$ with filtered seawater (as a control) followed by $\sim 30$ to $40 \mathrm{~s}$ with chemical signals. Between trials, the test chamber was flushed with filtered seawater for $60 \mathrm{~s}$ to remove residual chemicals. Note that flushing procedure returned the background neural activity to pre-stimulation levels. Arrow indicates the arrival of the stimulant to the antennule. Data shown are 3 replicates from a single louse

response to an 'OFF-ON' chemical signal and on average generated a 250 to $400 \%$ increase in firing frequencies for WFX. The peak firing rate occurred within 0.5 to $3 \mathrm{~s}$ after the stimulus arrived at the sensor. Full adaptation to a constant stimulation occurred within $15 \mathrm{~s}$ of peak response (Fig. 3). Individual neurons showed a pronounced dose response to increasing concentrations of WFX (Fig. 4), and typically displayed a log-linear increase in firing rate over some or all of the dose range. The response of most (14) of the neurons peaked at full strength WFX, whereas peak responses to dilutions of $10^{-1}$ and $10^{-2}$ occurred in 5 and 1 neurons, respectively. The pooled data showed a roughly log-linear dose-response function between approximately $10^{-3}$ to $10^{-1}$ WFX (Fig. 4). A concentration of $10^{-4}$ WFX was near or at the lower limit of detection, and there is some evidence that neural activity began to saturate at a concentration above $10^{-1}$ WFX.

Considerable inter-neuron variability in the presence and magnitude of responses to the isolated fractions was found, although the greatest and most consistent responses were to water-soluble fractions containing compounds between 1 and 10 kDa (Fig. 5). Responses to $>1$ and $<10 \mathrm{kDa}$ were present in all tested cells, whereas 3 and 4 cells responded to the $<1$ and $>10 \mathrm{kDa}$ fractions, respectively. Only 1 cell responded to the non-polar DE fraction despite the fact that the water fraction elicited responses from all cells at a level 


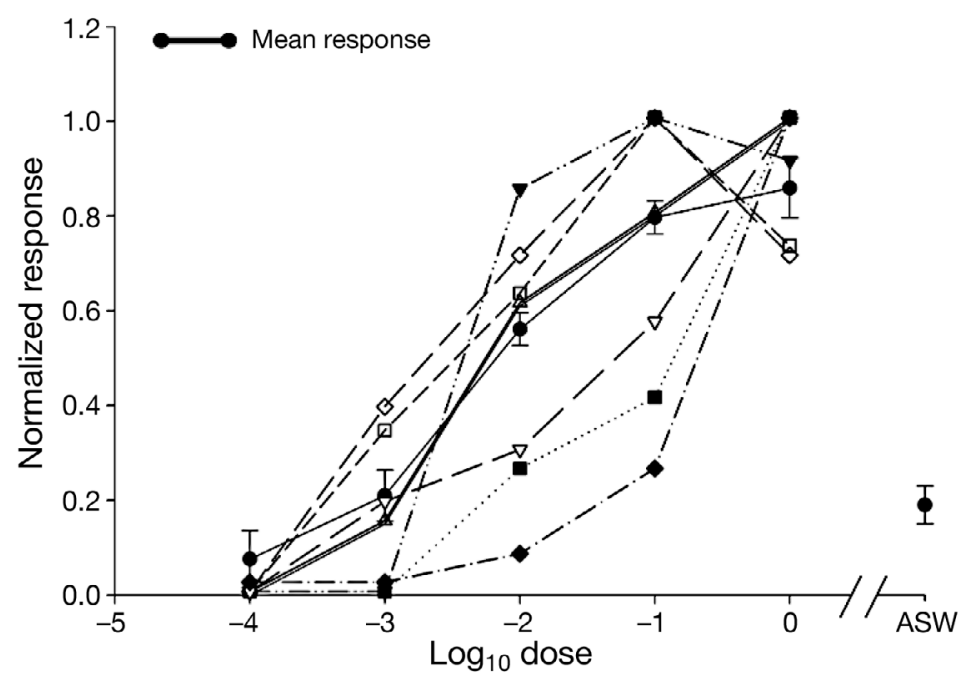

Fig. 4. Lepeophtheirus salmonis. Dose response of neurons to increasing concentrations of whole fish extract (WFX). Mean response $( \pm \mathrm{SE})$ of all neurons $(n=20)$ as well as representative responses of single neurons shown. Data were normalized to the maximum response of each individual neuron at a given dose. Response intensity refers to the number of spikes over the $30 \mathrm{~s}$ stimulus period as described in the text. Mean $( \pm \mathrm{SD})$ of responses to ambient seawater (ASW) is shown for comparison on the far right

not distinguishable from that of WFX; the mean normalized response of the water fraction $( \pm 1 \mathrm{SE})$ was $1.17 \pm 0.29$. The physiological activity in responses to WFX, $>1$ and $<10 \mathrm{kDa}$ fractions were significantly greater than the other 2 size fractions and the nonpolar compounds. In fact, confidence limits for the DE and $<1 \mathrm{kDa}$ fractions overlapped zero. The ANOVA shows a significant effect of fraction on response magnitude $\left(F_{1,60}=17.54, \mathrm{p}<0.001\right)$. The post-hoc test revealed that responses to $\mathrm{WFX}_{1}>1$ and $<10 \mathrm{kDa}$ fractions were not distinguishable from each other and were significantly different from the group composed of the $\mathrm{DE},<1$ and $>10 \mathrm{kDa}$ fractions. Thus, the watersoluble substances between 1 and $10 \mathrm{kDa}$ elicited spike frequencies that were approximately equal to that of WFX at the same concentration and so are sufficient to explain the responses to crude WFX.

\section{DISCUSSION}

In most marine invertebrates, chemosensation is an important sensory mode used to find food, mates, dwelling sites and hosts (McClintock \& Baker 1997, Devine et al. 2000, Zimmer \& Butman 2000). Understanding the properties of chemosensory neurons, including their threshold sensitivity, specificity, and response range has helped to determine how chemicals mediate resource finding (Carr 1978, Carr \& Derby
1986, Atema 1995, Weissburg 1997) and the distance over which they are effective. This investigation adds to the very limited characterization of chemosensory physiology in copepods, and in particular, the chemosensory responses in a parasitic form.

The physiological properties displayed by Lepeophtheirus salmonis chemoreceptors are similar to other crustaceans. Individual chemosensors typically display a 2 to 6 order of magnitude dynamic range. Different sensors along the same appendage show overlapping but not identical peak sensitivities, allowing the concentration range encoded by a population of neurons to exceed the capability of each individual neuron (Derby \& Atema 1982, Derby \& Steullet 2001). Although there is little available data on the physiological response of copepods to water-soluble chemical signals such as amino acids, most larger crustaceans have been shown to respond to micromolar or nanomolar concentrations of these chemicals with some investigators reporting thresholds as low as $10^{-6}$ to $10^{-7} \mathrm{M}$ (Derby \& Atema 1988).

The impetus for this work was to investigate the potential role of chemoreception by the parasitic copepod Lepeophtheirus salmonis in detecting hosts. To

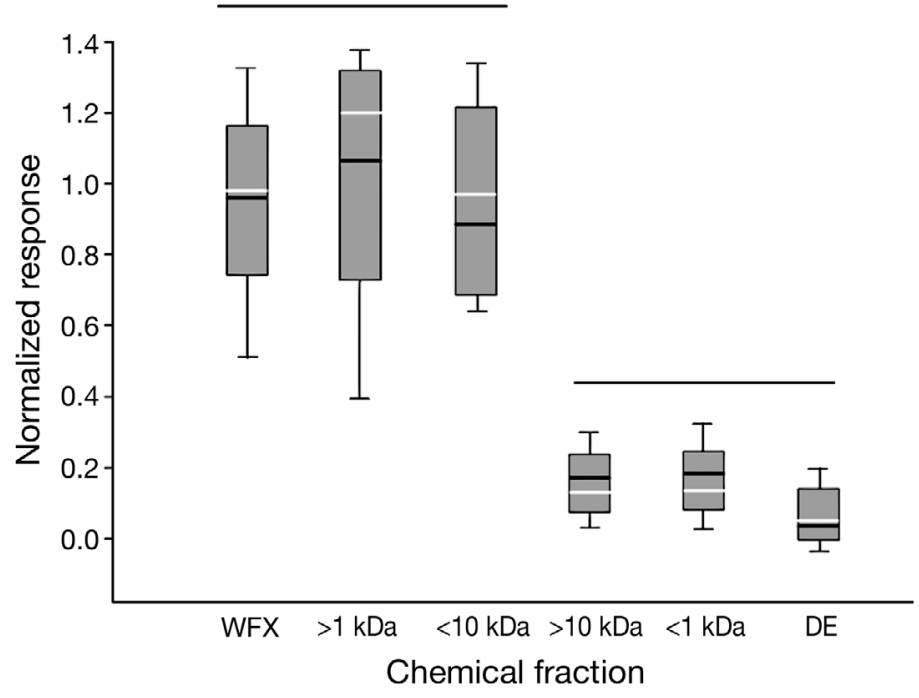

Fig. 5. Lepeophtheirus salmonis. Responses from individual neurons to polarity and molecular weight fractions of whole fish extract (WFX). Box plot of the response of neurons $(\mathrm{n}=$ 11) to each fraction at a dose of $10^{-1}$ relative to the crude extract shown. The WFX treatment is the neural response of the final presentation of this mixture and is meant to show both the relative magnitude of the response compared to the other fractions and act as an internal control for cell viability. Responses have been normalized to the response of each individual neuron $10^{-1}$ WFX and so this response measure ranges from 0 to 1. Dark lines represent the mean, white lines the median; box encloses 25th-75th percentile and whiskers the 10th-90th percentile. Lines above each treatment show conditions not significantly different based on a Tukey post-hoc test $(\alpha=0.05)$. DE: diethyl-ether solvent fraction 
effectively follow a plume of host-released chemical signals, chemosensory detection in L. salmonis must show 3 general properties: (1) a rapid increase in neural activity to stimuli; (2) adaptation to a constant chemical signal (so the louse can detect if it is moving across an region of constant chemical concentration); and (3) a clear dose response such that the louse can respond to a large dynamic range in the chemical signal intensity. The data clearly shows that chemosensors of adult $L$. salmonis respond to chemicals emanating from salmon flesh, with adaptation to monotonic concentrations within seconds. Furthermore, $L$. salmonis showed a clear dose response function over a range of 4 orders of magnitude. These results suggest that that chemical cues do provide information to the parasite concerning the presence of a host. These results are not unexpected given the importance of chemical cues in copepod aggregation (Poulet \& Ouellet 1982, Woodson et al. 2005), food choice (Cowles et al. 1988) and mate identification (Doall et al.1998, Bagøien \& Kiørboe 2005). This supports previous observations showing that copepodid (Bailey et al. 2006) and adult (Ingvarsdóttir et al. 2002b) L. salmonis are attracted to salmon-conditioned water and extracts in y-tube choice experiments.

Our partial characterization of salmon lice chemostimulants suggests that active components are water-soluble molecules between 1 and $10 \mathrm{kDa}$. Although we did occasionally see responses to fractions containing larger and smaller substances, these were less frequent and small compared to responses to the $>1$ and $<10 \mathrm{kDa}$ fractions, which were always similar in magnitude to the response to WFX. Only one cell responded to the DE fraction and displayed a level of activity well below that of either WFX or the 2 stimulatory water-soluble fractions. These results also are consistent with known properties of crustacean chemosensors. Responses to polar molecules 1 to $10 \mathrm{kDa}$ have repeatedly been demonstrated in physiological assays, although most investigations generally have not utilized potential stimulants larger than this range (Weissburg et al. 2002). Crustacean chemosensors typically are responsive to a small number of different compounds, with individual chemosensors expressing sensitivity to different suites of chemical signals (Derby \& Atema 1988). Thus, it is not particularly surprising to observe that some sensors respond to fractions that, in general, evoke little response from the majority of cells, and our working hypothesis is that water-soluble molecules between 1 and $10 \mathrm{kDa}$ are the major sources of chemosensory information for salmon lice.

The chemical nature of stimulatory molecules and their role in specific behavioral processes must be confirmed by suitable behavioral assays (e.g. Bailey et al.
2006). Direct assays of attraction to fractions from salmon-conditioned water in larval and adult sea lice suggest responses to both the vacuum distillate and solid phase extracts, although the distillate was generally more stimulatory. These fractions would include volatile compounds $(<1 \mathrm{kDa})$ and relatively nonvolatile components $(>1 \mathrm{kDa})$, respectively, so that the results of our electrophysiological assays are somewhat consistent with behavioral trials. However, the magnitude of responses in chemosensory afferents is not always correlated with the degree of behavioral attraction. Central inhibition based on the activity of peripheral detectors can be important in some chemosensory discrimination tasks, particularly mate identification in insects (Baker \& Cardé 1977, Vickers 2000), and possibly, food choice in lobsters (Zimmer-Faust et al. 1984).

A comparison between thresholds found in this study and other reported values are not straightforward. In most studies test compounds were chemically characterized, fully homogenized and diluted to determine threshold concentrations. In an effort to standardize the chemical signal while still maintaining a more ecologically relevant signal, we conditioned known amounts of water with $1 \mathrm{~h}$ exposures to a known quantity of fish flesh. This protocol mobilized a significantly smaller portion of the potential chemical signals within the salmon meat than the homogenized methods, but provides a more ecologically and behaviorally realistic stimulus (Ingvarsdóttir et al. 2002b, Bailey et al. 2006). Since the levels of these putative lice stimulants found in whole tissue samples are clearly significantly higher than the concentrations produced by the extraction method used in this study, our values can only provide a highly conservative estimate of detection thresholds for Lepeophtheirus salmonis.

Whole tissue levels of amino acids, amines and other feeding stimulants range from approximately $10^{-2}$ to $10^{-5} \mathrm{M}$ in a variety of fish (including pink salmon Oncorhynchus gorbuscha; Carr \& Derby 1986). Based upon the threshold sensitivity of $10^{-3}$ dilution of WFX $\left(10^{-4}\right.$ of fish meat) found in this study, the minimum sensitivity of Lepeophtheirus salmonis to a similarly stimulatory compound would be within the range of $10^{-6}$ to $10^{-8} \mathrm{M}$. These values are similar to those reported for larger crustaceans. For example, chemosensory neurons on the mouthparts of spiny lobster Panulirus argus and P. interruptus have thresholds between $10^{-4}$ and $10^{-6} \mathrm{M}$ (Garm et al. 2003). Thus our data suggests that, at a minimum, threshold levels of chemosensory stimulation for $L$. salmonis adults are likely to occur when they are in close proximity to a single host or near a large aggregation of salmon (e.g. a migratory population or sea cage residents). Close 
range detection could be useful in several different contexts. Although the primary infective stages are thought to be the motile planktonic copepodids (Costello 2006), sub-adult and adult stages move between fish housed in outdoor pens or laboratory tanks (Ritchie 1997). Adult males were the most likely to move, which may be a mechanism for males to relocate to fish with potential mates. Detection of chemical cues from potential hosts could help to either guide adults to a new host, or facilitate contact by causing increases in activity levels that cause lice to remain in areas where potential hosts occur.

Based on the high sensitivity found in other crustaceans, long distance detection of salmon hosts by Lepeophtheirus salmonis is possible. However, long range detection may not provide much advantage for tracking and attaching to a specific host because salmon swim considerably faster and further than $L$. salmonis. Yet, sensitivity to low odor concentrations may still increase the ability of adult lice to locate a host. In the absence of other sensory cues, behavioral observations show that low concentrations of salmonconditioned water induced a pronounced increase in swimming speeds (D. M. Fields et al. unpubl.) that theoretically should increase the encounter rates of salmon lice with potential hosts.

Although it is clear that the relative importance of different sensory cues can change during ontogeny (Johnson \& Albright 1991, Poulin 1998, Flamarique et al. 2000), either because of the development of the sensory organs (Wahl et al. 1993), and/or due to differences in ecological conditions (Weissburg \& Zimmer-Faust 1991, Quirt \& Lasenby 2002), it is likely that the chemosensory abilities we document in adults also reflect sensory mechanisms in copepodids that are useful for host location and/or identification. In fact, behavioral assays show that both copepodid and adult Lepeophtheirus salmonis are attracted to similar crude fractions of salmon-conditioned water and isophorone, inducing high activity levels in adults and orientation of copepodids in y-tube assays (Ingvarsdóttir et al. 2002a,b, Bailey et al. 2006). Furthermore, scanning electron microscopy (SEM) data (Johnson \& Albright 1991, Gresty et al. 1993) shows that the number of sensors and their exterior morphology are largely conserved within the entire infectious stage (from $7 \mathrm{~d}$ old until the adult stage), suggesting that these lice develop acuity for host-related signals once they have become infectious and maintain this capability to the adult stage. To date, no systematic study has been done on the ontogenetic changes in sensor morphology and sensitivity of L. salmonis. Such a study is certainly warranted in light of the large economic and potentially ecological damage done by L. salmonis.
Acknowledgements. This work was financed by The Research Council of Norway (Projects 134613/120 and 153274/120) and by the Norwegian Institute of Marine Research's internal project 'Sensory Biology and Behaviour of the Early Life Stages of Aquatic Organisms'. H.I.B. is supported by the Institute of Marine Research, Norway, The Research Council of Norway and the Inter-Research Science Center. D.M.F. was supported by matching funds provided by the Georgia Institute of Technology (GIT) and funding through the National Science Foundation (NSF) (IBN 024077) awarded to D.M.F. and M.J.W.

\section{LITERATURE CITED}

Atema J (1995) Chemical signals in the marine-environment - dispersal, detection, and temporal signal analysis. Proc Natl Acad Sci USA 92:62-66

Bagøien E, Kiørboe T (2005) Blind dating-mate finding in planktonic copepods. I. Tracking the pheromone trail of Centropages typicus. Mar Ecol Prog Ser 300:105-115

Bailey RJE, Birkett MA, Ingvarsdóttir A, Mordue (Luntz) AJ, Mordue W, O'Shea B, Pickett JA, Wadhams LJ (2006) The role of semiochemicals in host location and non-host avoidance by salmon louse (Lepeophtheirus salmonis) copepodids. Can J Fish Aquat Sci 63:448-456

Baker TC, Cardé RT (1977) Disruption of gypsy moth male sex pheromone behaviour by high frequency sound. Environ Entomol 7:45-52

Beamish RJ, Neville CM, Sweeting RM, Ambers N (2005) Sea lice on adult Pacific salmon in the coastal waters of Central British Columbia, Canada. Fish Res 76:198-208

Bron JE, Sommerville C, Rae GH (1993) Aspects of the behaviour of copepodid larvae of the salmon louse Lepeophtheirus salmonis (Krøyer, 1837). In: Boxshall GA, Defaye D (eds) Pathogens of wild and farmed fish: sea lice. Ellis Horwood, Chichester, p 125-142

Buchmann K, Bresciani J (1997) Microenvironment of Gyrodactylus derjavini on rainbow trout Oncorhynchus mykiss: association between mucous cell density in skin and site selection. Parasitol Res 84:17-23

Buchmann K, Nielsen ME (1999) Chemoattraction of Ichthyophthirius multifiliis (Ciliophora) theronts to host molecules. Int J Parasitol 29:1415-1423

Carr WES (1978) Chemoreception in the shrimp, Palaemonetes pugio, the role of amino acids and betaine in elicitation of feeding responses by extracts. Comp Biochem Physiol 61:127-131

Carr WES, Derby CD (1986) Behavioral chemoattractants for the shrimp, Palaemontes pugio: identification of active components in food extracts and evidence of synergistic mixture interactions. Chem Senses 11:49-64

Costello MJ (2006) Ecology of sea lice parasitic on farmed and wild fish. Trends Parasitol 22:475-483

Cowles TJ, Olson RJ, Chisholm SW (1988) Food selection by copepods: discrimination on the basis of food quality. Mar Biol 100:41-49

Derby CD, Atema J (1982) The function of chemo- and mechanoreceptors in lobster (Homarus americanus) feeding behavior. J Exp Biol 98:317-327

Derby CD, Atema J (1988) Chemoreceptor cells in aquatic invertebrates: peripheral mechanisms of chemical signal processing in decapod crustaceans. In: Atema J, Fay RR, Popper AN, Tavolga WN (eds) Sensory biology of aquatic animals. Springer-Verlag, New York, p 365-385

Derby CD, Stuellet P (2001) Why do animals have so many receptors? The role of multiple chemosensors in animal 
perception. Biol Bull 200:211-215

Devine GJ, Ingvarsdóttir A, Mordue W, Pike AW, Pickett J, Duce I, Mordue AJ (2000) Salmon lice, Lepeophtheirus salmonis, exhibit specific chemotactic responses to semiochemicals originating from the salmonid, Salmo salar. J Chem Ecol 26:1833-1847

Doall MH, Colin SP, Strickler JR, Yen J (1998) Locating a mate in 3D: the case of Temora longicornis. Philos Trans R Soc Lond Ser B 353:681-689

Fields DM, Yen J (2002) Fluid mechanosensory stimulation of behavior from a planktonic marine copepod Euchaeta rimana Bradford. J Plankton Res 24:747-755

Fields DM, Shaeffer DS, Weissburg MJ (2002) Mechanical and neural responses from the mechanosensory hairs on the antennule of Gaussia princeps. Mar Ecol Prog Ser 227:173-186

Finstad B, Bjørn PA, Grimnes A, Hvidsten NA (2000) Laboratory and field investigations of salmon lice (Lepeophtheirus salmonis, Krøyer) infestation on Atlantic salmon (Salmo salar L.) post-smolts. Aquacult Res 31:795-803

Flamarique IN, Browman HI, Bélanger M, Boxaspen K (2000) Ontogenetic changes in visual responses of the parasitic salmon louse, Lepeoptheirus salmonis. J Exp Biol 203: 1649-1657

Garm A, Hallberg E, Høeg JT (2003) Role of maxilla 2 and its setae during feeding in the shrimp Palaemon adspersus (Crustacea: Decapoda). Biol Bull 204:126-137

Gresty KA, Boxshall GA, Nagasawa K (1993) Antennulary sensors of the infective copepod larva of the salmon louse Lepeophtheirus salmonis (Copepoda: Caligidae). In: Boxshall GA, Defaye D (eds) Pathogens of wild and farmed fish: sea lice. Ellis Horwood, Chichester, p 83-98

Haas W (2003) Parasitic worms: strategies of host finding, recognition and invasion. Zoology 106:349-364

Haas W, Stiegeler P, Keating A, Kullmann B, Rabenau H, Schonamsgruber E, Haberl B (2002) Diplostomum spathaceum cercariae respond to a unique profile of cues during recognition of their fish host. Int $\mathrm{J}$ Parasitol 32: $1145-1154$

Heuch PA, Karlsen HE (1997) Detection of infrasonic water oscillations by copepodids of Lepeophtheirus salmonis. (Copepoda: Caligida). J Plankton Res 19:735-747

Heuch PA, Doall M, Yen J (2007) Water flow around a fish mimic attracts a parasitic and deters a planktonic copepod. J Plankton Res 29:3-16

Hilborn R (2006) Salmon-farming impacts on wild salmon. Proc Natl Acad Sci USA 103:15277

Ingvarsdóttir A, Birkett MA, Duce I, Mordue W, Pickett JA, Wadhams LJ, Mordue (Luntz) AJ (2002a) Role of semiochemicals in mate location by parasitic salmon louse. Lepeophtheirus salmonis. J Chem Ecol 28:2107-2117

Ingvarsdóttir A, Birkett MA, Duce I, Genna RL, Mordue W, Pickett JA, Wadhams LJ, Mordue (Luntz) AJ (2002b) Semiochemical strategies for sea louse control: host location cues. Pest Manag Sci 58:537-545

Johnson SC, Albright LJ (1991) The development stages of Lepeophtheirus salmonis (Krøyer, 1837) (Copepoda: Caligidae). Can J Zool 69:929-950

Krkosek M, Lewis MA, Morton A, Frazer LN, Volpe JP (2006) Epizootics of wild fish induced by farm fish. Proc Natl Acad Sci USA 103:15506-15510

Luntz AJM (2003) Arthropod semiochemicals: mosquitoes, midges and sealice. Biochem Soc Trans 31:128-133

Editorial responsibility: David Marcogliese,

Montréal, Quebec, Canada
McClintock JB, Baker BJ (1997) A review of the chemical ecology of Antarctic marine invertebrates. Am Zool 37: 329-342

Mikheev VN, Pasternak AF, Valtonen ET (2003) How do fish ectoparasites Argulus spp. (Crustacea: Branchiura) match with their hosts at the behavioural and ecological scales? Zh Obshch Biol 64:238-247

Mikheev VN, Pasternak AF, Valtonen ET (2004) Tuning host specificity during the ontogeny of a fish ectoparasite: behavioural responses to host-induced cues. Parasitol Res 92:220-224

Okubo A, Armstrong RA, Yen J (2001) Diffusion of 'smell' and 'taste': chemical communication. In: Okubo A, Levin SA (eds) Diffusion and ecological problems: modern perspectives. Springer-Verlag, New York, p 107-126

Pike AW, Wadsworth SL (1999) Sea lice on salmonids: their biology and control. Adv Parasitol 44:234-337

Poulet SA, Ouellet G (1982) The role of amino acids in the chemosensory swarming and feeding of marine copepods. J Plankton Res 4:341-361

Poulin R (1998) Evolutionary ecology of parasites. From individuals to communities. Chapman \& Hall, London

Quirt J, Lasenby D (2002) Cannibalism and ontogenetic changes in the response of the freshwater shrimp Mysis relicta to chemical cues from conspecific predators. Can J Zool 80:1022-1025

Ritchie G (1997) The host transfer ability of Lepeophtheirus salmonis (Copepoda: Caligidae) from farmed Atlantic salmon Salmo salar L. J Fish Dis 20:153-157

Vickers NJ (2000) Mechanisms of animal navigation in odor plumes. Biol Bull 198:203-212

Wahl CM, Mills EL, McFarland WN, DeGisi JS (1993) Ontogenetic changes in prey selection and visual acuity of the yellow perch, Perca flavescens. Can J Fish Aquat Sci 50:743-749

Weissburg MJ (1997) Chemo- and mechanosensory orientation by crustaceans in laminar and turbulent flows: from odor trails to vortex streets. In: Lehrer M (ed) Orientation and communication in arthropods. Birkhauser Verlag, New York, p 215-246

Weissburg MJ, Zimmer-Faust RK (1991) Ontogeny versus phylogeny in determining patterns of chemosensorymediated behavior: initial studies with fiddler crabs. Biol Bull 181:205-215

Weissburg MJ, Ferner MC, Pisut DP, Smee DL (2002) Ecological consequences chemically-mediated prey perception. J Chem Ecol 28:1953-1957

Woodson CB, Webster DR, Weissburg MJ, Yen J (2005) Response of copepods to physical gradients associated with structure in the ocean. Limnol Oceanogr 50:1552-1564

Wootten R, Smith JW, Needham EA (1982) Aspects of the biology of the parasitic copepods Lepeophtheirus salmonis and Caligus elongatus on farmed salmonids and their treatment. Proc R Soc Edinb 81:185-197

Yen J, Okubo A (2002) Particle and prey detection by mechanoreceptive copepods: a mathematical analysis. Hydrobiologia 480:165-173

Zimmer RK, Butman CA (2000) Chemical signalling processes in the marine environment. Biol Bull (Woods Hole) 198: $168-187$

Zimmer-Faust RK, Michel WC, Tyre JE, Case JF (1984) Chemical induction of feeding in California spiny lobster, Panulirus interruptus (Randall). J Chem Ecol 10:957-971

Submitted: February 12, 2007; Accepted: September 25, 2007 Proofs received from author(s): November 9, 2007 